Article

\title{
Territorializing International Travel Emissions: Geography and Magnitude of the Hidden Climate Footprint of Brussels
}

\author{
Kobe Boussauw ${ }^{1, *}$ and Jean-Michel Decroly ${ }^{2}$ \\ ${ }^{1}$ Cosmopolis Centre for Urban Research, Department of Geography, Vrije Universiteit Brussel, 1050 Brussels, Belgium; \\ E-Mail: kobe.boussauw@vub.be \\ 2 Institute for Environmental Management and Land-Use Planning, Department of Geosciences, Environment and Society, \\ Université Libre de Bruxelles, 1050 Brussels, Belgium; E-Mail: jean-michel.decroly@ulb.ac.be \\ * Corresponding author
}

Submitted: 10 December 2020 | Accepted: 25 February 2021 | Published: 9 June 2021

\begin{abstract}
In the present article we investigate the geography and magnitude of the climate footprint of long-distance travel with Brussels, Belgium, as a destination. The internationally networked position of this city goes hand in hand with a strong dependence on international mobility, which largely materializes in impressive volumes of long-distance travel and associated consumption of important amounts of fossil fuel. Despite a surge in concerns about global warming, the climate footprint of most international travel, notably air travel, is not included in the official national and regional climate inventories, or in other words, it is not territorialized. The official climate footprint of the Brussels-Capital Region attained $3.7 \mathrm{Mton}$ $\mathrm{CO}_{2}$ eq per year (in 2017). Based on our exploratory calculations, however, the total estimated climate footprint of all Brussels-bound international travel equalled an additional 2.7 Mton $\mathrm{CO}_{2}$ eq. In terms of geographical distribution, over $70 \%$ of international travellers to Brussels come from Europe, while these represent only $15 \%$ of the climate footprint of all international travel to Brussels. We conclude that the practice of not allocating emissions caused by international travel to territorial units has kept the magnitude and complexity of this problem largely under the radar and contributes to the lack of societal support for curbing growth of international aviation.
\end{abstract}

\section{Keywords}

air travel; Brussels; cities; climate footprint; tourism

Issue

This article is part of the issue "Cities, Long-Distance Travel, and Climate Impacts" edited by Jukka Heinonen (University of Iceland, Iceland) and Michał Czepkiewicz (University of Iceland, Iceland / Adam Mickiewicz University in Poznań, Poland).

(C) 2021 by the authors; licensee Cogitatio (Lisbon, Portugal). This article is licensed under a Creative Commons Attribution 4.0 International License (CC BY).

\section{Introduction: A Territorial Approach to the Climate Footprint of International Travel}

Although the climate footprint of long-distance travel is not a new object of study in the academic literature (see, e.g., Patterson \& McDonald, 2004; Sun, Cadarso, \& Driml, 2020; Wood, Bows, \& Anderson, 2010), the theme has only recently seeped into the public climate debate (Wolrath Söderberg \& Wormbs, 2019) and is not included in often-cited indicators such as national greenhouse gas inventories that need to be maintained by all industrialized countries ('Annex I countries') under the
Kyoto protocol (Gössling, 2013), according to prevailing agreements. While in recent years serious efforts were done to also make aviation accountable for its contribution to global warming, through instruments such as the EU Emissions Trading System (within the European Economic Area, since 2012) and the aviation sector's own carbon offset scheme CORSIA (as from 2021; Larsson, Elofsson, Sterner, \& Åkerman, 2019), governments of nations, regions, or cities are not eager to recognize ownership of the emissions that are associated with longdistance travel towards or from their territories. This attitude is implicitly supported by national greenhouse 
gas inventory regulations that do not allocate such emissions to individual countries (Warnecke, Schneider, Day, La Hoz Theuer, \& Fearnehough, 2019). The complexity of the climate issue, to which both embedded emissions in imported products and the contribution of long-distance travel are of great importance, is hardly recognized in governmental climate policy plans. Although an inventory of such plans is beyond the scope of this article, we quote here the official climate policy plan of our case study, the Brussels-Capital Region, in which none of both themes is mentioned (Brussels-Capital Region, 2019). The current territorial approach to the allocation of climate footprints causes an important bias in the way the climate issue is viewed by the public and by policy makers. However, both emissions from international transport and imported products are caused by consumers, citizens, and organizations that are established in certain and identifiable countries and regions. The emissions from international transport are not only absent from the climate inventories but seem also underexposed in the climate debate itself.

In fact, the territorial focus of climate inventories ignores the internationalization of production chains and the structural shift towards service industries (tertiarization) of the economy of the most developed countries. Emissions are viewed as soil-bound affairs, while economic activities have increasingly become footloose. The shift from a manufacturing to a service economy means that emissions got detached from geolocalized production processes and shifted towards the geographically diffuse sector of long-distance transport. Reductions within national industrial production are clearly visible in the national climate inventories. However, increases in international travel associated with the rise of the service industry remain invisible in these inventories (Afionis, Sakai, Scott, Barrett, \& Gouldson, 2017; Davis \& Caldeira, 2010; Ottelin et al., 2019).

But international travel does not only support the manufacturing industry. The knowledge industry is also an important consumer of air kilometres (Achten, Almeida, \& Muys, 2013; Ciers, Mandic, Toth, \& Op't Veld, 2019; Klöwer, Hopkins, Myles, \& Higham, 2020), including participation in scientific meeting (Burtscher et al., 2020; Nevins, 2014) just like higher education (Davies \& Dunk, 2015), notably international student mobility (Shields, 2019), international politics, business travel (Kitamura, Karkour, Ichisugi, \& Itsubo, 2020; Poom, Orru, \& Ahas, 2017), sports (Collins, Munday, \& Roberts, 2012; Pereira, Filimonau, \& Ribeiro, 2019), culture (Bottrill, Liverman, \& Boykoff, 2010; Collins \& Cooper, 2017; Connolly, Dupras, \& Séguin, 2016), tourism (e.g., Dube \& Nhamo, 2019; Luo, Becken, \& Zhong, 2018; Sharp, Grundius, \& Heinonen, 2016; Smith \& Rodger, 2009), and all kinds of visits by foreigners to their families and friends (Sun \& Pratt, 2014). Within the academic sector, Erasmus programmes financially support European students to study away from home, while compensation increases with travel distance. Researchers are encour- aged to develop international networks and are therefore supposed to travel on a regular basis, often by air (Arsenault, Talbot, Boustani, Gonzàles, \& Manaugh, 2019; Wynes, Donner, Tannason, \& Nabors, 2019). Also, international politics, such as European institutions, have an important ecological footprint. Moreover, relocation of families of which one member is active in an international sector usually entails additional journeys, for example by relatives and friends who come over for a visit. The last kind of journeys fall under the category of 'tourism,' which in the Global North comprises the bulk of all international journeys (Dobruszkes, Ramos-Pérez, $\&$ Decroly, 2019). The emissions associated with such trips are not visible in the national climate inventories.

\section{The Case of Brussels, Belgium: A Focal Point of the Travel-Climate Issue}

The aim of this article is to provide insight into the geography and magnitude of the climate footprint of the international attractiveness of a city with an important international position as a business and political centre, in relation to the official, territorialized climate footprint of this city. We will explore this issue for the case study of Brussels by taking a traditional bottom-up approach that estimates climate footprint based on the distribution of transport modes used by travellers (Sun \& Drakeman, 2020). The choice for Brussels was inspired by the role played by this city as a forum for international political decision-making, which includes European climate policy, while the city and the activities it hosts are an important generator of international travel and the related climate footprint (Van Parijs \& Van Parys, 2010). In what follows, we consider the Brussels-Capital Region, which is one of the three administrative regions in Belgium (next to Flanders and Wallonia), home to 1.2 million residents, out of 11.5 million Belgians.

We start with a look at the official climate footprint of Brussels, in relation to its geographical context. In 2017, according to the Belgian greenhouse gas inventory, the total climate footprint amounted to 114.5 Mton $\mathrm{CO}_{2}$ eq (FPS Public Health, Food Chain Safety and Environment, 2019), of which only 3.7 Mton $\mathrm{CO}_{2} \mathrm{eq}$ (3.2\%) was on account of the Brussels-Capital Region (Bruxelles Environnement, 2019). This remarkably modest contribution is even more noteworthy when we learn that in 2017 the Brussels-Capital Region not only housed $10.5 \%$ of the Belgian population, but even generated $17.8 \%$ of the Belgian gross domestic product. These figures are grist to the mill of those who claim that city dwellers, by definition, live more sustainably than suburban or rural dwellers, or as Banister (2008, p. 73) put it: "The city is the most sustainable urban form." Indeed, the official carbon intensity of the Brussels economy is around 5.5 times smaller than that of Belgium as a whole. However, just as Belgium is externalizing an important part of the emissions for which the Belgian economy is responsible to low-wage countries and to all sorts of 
foreign travel destinations, Brussels is externalizing an even larger part of its emissions to its hinterland, being an important consumer of food and industrial products, almost none of which are produced on its own territory. Also, no airports (Boussauw \& Vanoutrive, 2019) or seaports are located within the modest area of the territory of Brussels, which means that even the climate intensity of travel by Brussels' residents, which may be well higher than the Belgian average (Czepkiewicz, Heinonen, \& Ottelin, 2018), is invisible in any relevant databases.

Mapping the actual climate footprint of the BrusselsCapital Region is beyond the scope of this article. Instead, we aim to understand the geography of the climate footprint of inbound international travel, and identify any knowledge gaps that may prevent us from doing so in a comprehensive and reproducible manner. This concerns all international journeys with Brussels as a destination, regardless of the purpose of the trip (business, politics, science, education, tourism). In this way, we subscribe to an existing tradition of research into sustainable tourism (Gössling et al., 2005; Le \& Nguyen, 2021; Sun, 2014), although we expand leisure with business travel. In that context, Peeters and Schouten (2006), for example, already investigated the ecological footprint of tourism to and in Amsterdam. A similar assessment was recently carried out for Barcelona (Rico et al., 2019). In both cases, the results show that the overwhelming majority of the climate footprint of tourist visits are attributable to travel to the destination, in particular to long-distance air travel. These studies take into account the climate footprint related to touristic activities in the destination (accommodation, leisure and professional activities, intra-urban transport). However, they measure the climate footprint of transport to the destination just roughly, distinguishing between large categories (e.g., short, medium, long haul travel; or classifying trip origins merely by continent). In our case, we have sought to measure the climate footprint of travel from each country of origin. Such an approach, which considers at the same time the territory where the tourist activities take place (here Brussels) and the territories where the tourists come from is still quite rare in the research field of climate footprint of tourism (see Becken, 2002, for international passenger air travel to New Zealand; Dawson, Stewart Lemelin, \& Scott, 2010, for polar bear viewing tourism in Churchill, Canada; El Hanandeh, 2013, for the pilgrimage to Mecca; Lenzen et al., 2018, for tourism-related global carbon flows between 160 countries; and Sharp et al., 2016, on Iceland). Finally, it is important to note that our bottom-up approach is only one possible option, prompted by our research question and the availability of data. By nature, this approach suffers from many limitations (Lenzen et al., 2018). In order to arrive at a more global picture of the climate footprint of international travel patterns, it might however make more sense to consider the resident as a statistical unit, rather than the visitor, as was argued by Larsson, Kamb, Nässén, and Åkerman (2018).

\section{Method}

Various bottom-up methods have been developed to assess the importance of the climate footprint of tourist trips to specific destinations, which usually and deliberately do not include outward trips made by residents of the city or region in question (e.g., Dwyer, Forsyth, Spurr, \& Hoque, 2010; Peeters \& Schouten, 2006; Rico et al., 2019). Other studies focus specifically on estimating the climate footprint of the residents of a certain area, such as Eijgelaar, Peeters, de Bruijn, and Dirven (2017) or Larsson et al. (2018). In what follows we will stick to the first of both approaches. The studies referred to above combine data on the number and origin of international overnight visitors (or 'tourists' according to definition of the World Tourism Organization (2010)) with modal split figures that vary according to their origin, trip lengths, and standardized emission rates per passenger kilometre. In this article, we will use the terms 'overnight visitor' and 'tourist' as synonyms. When making a distinction between overnight visitors or tourists who are on holiday or on business trip, we will use the concepts of 'leisure' versus 'business.' The time frame of our study is the year 2018 and the unit of analysis is one round trip of inbound travel of one international passenger.

\subsection{Number and Origin of Overnight Visitors}

With respect to the number and the origins of overnight visitors, the quality of available data sets considerably varies between countries and even between cities. Two key determinants are, first, the way in which the geographical basis of data collection is demarcated, and second, the tourist counting method that was applied. In the case of the Brussels-Capital Region, the statistical basis includes all officially registered tourist accommodation. This comprises around 180 hotel and hotel-like branches with a total capacity of 35,000 beds, 9 hostels offering around 1,400 beds, and around 100 other accommodations such as bed and breakfast and tourist residences additionally offering about 500 beds. However, this statistical basis covers only part of the actual offer of commercial accommodation. According to Wayens et al. (2020), covering the year 2017, nearly 34,000 beds available on the Airbnb and Home Away platforms would be off the radar. Not taking into account this vast set of unregistered accommodation, which is more or less equivalent to the capacity in registered branches, will lead to underestimating tourist arrivals by around $30 \%$. Furthermore, it should be borne in mind that these figures are still exclusive of informal accommodation offered by friends and family members, a phenomenon which is probably important in Brussels, taking into account the high proportion of foreign residents, particularly those originating from wealthy states such as the European Union, North America, and Japan. According to a survey carried out in 2018-19 in the Brussels museums, one fifth of all international overnight visitors in Brussels 
were staying with friends or family members (Decroly \& Tihon, 2019).

Even though statistics of tourist accommodation in the Brussels-Capital Region are incomplete, they provide detailed data on international arrivals in officially registered accommodation. In these, for each guest or group of guests, staff members are required to collect information about the state of residence, the purpose of the stay, the day of departure, and the number of nights spent. The data is then transferred to Statistics Belgium, which procures detailed tables of the number of arrivals and overnight stays by purpose, for each country of residence. Residence is an important variable here, since it corresponds more frequently to the actual place of departure of the trip, compared to nationality (a variable that is more commonly collected than residence).

\subsection{Travel Modal Split According to Country of Origin}

Official statistics on tourist arrivals in Brussels do not contain information on the mode of transport used. Therefore, we complement these statistics with data from visitor surveys collected by the Art Cities Research project (Toerisme Vlaanderen, 2018). This survey was conducted between April 2017 and April 2018 among 1,400 people staying in Brussels for leisure purposes and includes travel mode choices by tourists from the nine most important sending countries that visited Brussels.

At first glance, a surprising share, larger than or equal to $60 \%$, of incoming trips by leisure tourists from Russia, China, Japan, and the United States seems to be over land travel (car and coach statistics cover ferry trips from the UK; Figure 1). This result is indicative of the way in which many international tourist trips materialize. A majority of intercontinental overnight visitors take advantage of the opportunity to visit multiple destinations, e.g., using the format of the low-cost coach tours that are offered by many non-European tour operators and have become popular, in particular among Chinese tourists (Arlt, 2013; Bui \& Trupp, 2014; Xiang, 2013). Independent multi-destination tours are also common practice among Japanese, Korean, or Chinese tourists (Pendzialek, 2016). Although less well documented, this phenomenon is probably common as well among individual overnight visitors from other distant markets, such as the United States, Canada, or Australia.

But even if tourists from distant markets frequently visit Europe in the form of a tour, which mainly involves surface transport, the initial trip to Europe was mostly a flight. The Art Cities Research (Toerisme Vlaanderen, 2018) summary tables confirm that about $100 \%$ of these incoming trips consist of air travel. This illustrates how difficult it is to determine the footprint of travel, which becomes even more problematic in attempts to allocate corresponding climate footprints to territorial units (such as the Brussels-Capital Region). It is not obvious whether we need to take into account the mode of transport used to get to Brussels, the one used to reach Europe, or both at the same time. Ideally, both would be combined, by distributing the emissions linked to transport to Europe across the various destinations visited, and by calculating the specific emissions that are associated with intraEuropean travel to Brussels. However, given the lack of data on intra-European tours by leisure tourists from distant markets, we cannot implement such a strategy. Instead, in line with the Art Cities Research summary tables, we assumed that all incoming travel of leisure overnight visitors in the Brussels-Capital Region that originate from a remote location at $2,000 \mathrm{~km}$ or more were done by air.

In the current article, we use the Art Cities Research data to estimate the distribution of international arrivals in Brussels by travel mode, according to the overnight visitors' origins. Although the data relate only to a limited number of origins, only cover leisure trips, and do not resolve the complicated question of multi-destination

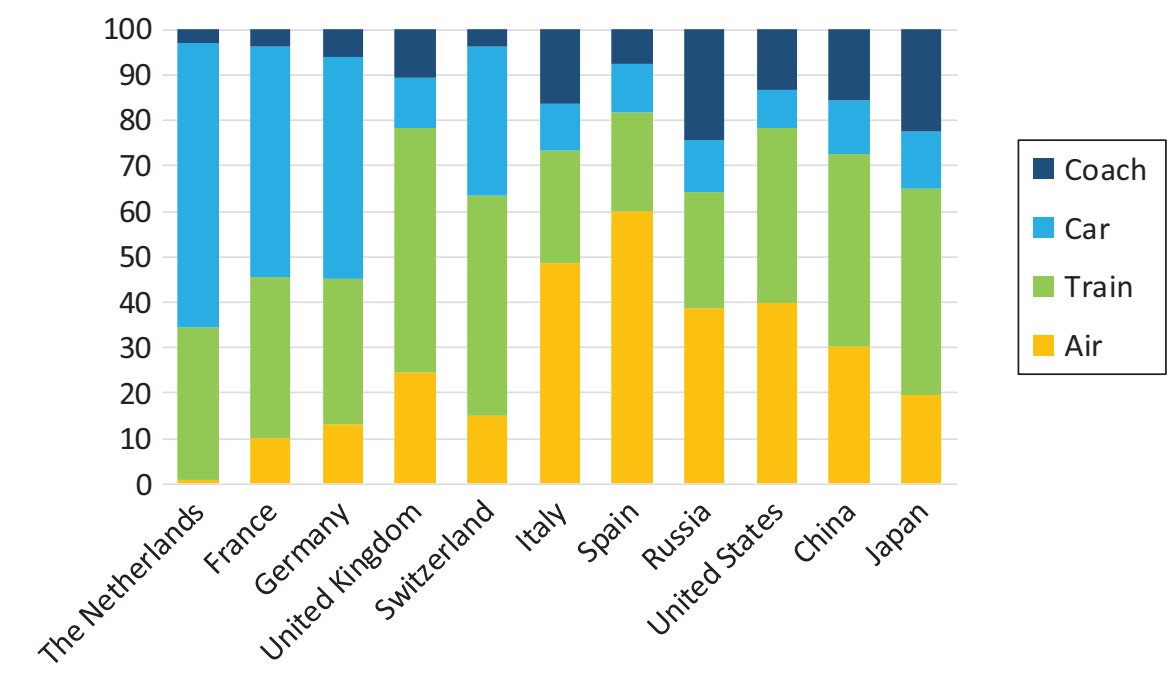

Figure 1. Modal split of tourist arrivals (leisure purpose only) in Brussels by origin country, according to the Art Cities Research survey (2017-2018). Source: Toerisme Vlaanderen (2018). 
tours in which tourists from distant markets take part, they offer the advantage that they represent real trips instead of modelled ones, as was done by Gunter and Wöber (2019), among other studies.

However, Fiorello, Martino, Zani, Christidis, and Navajas-Cawood (2016) show that for equal trip lengths modal split differs, depending on travel purpose. Statistics on international arrivals in Brussels distinguish between leisure and business trips, which urges us to correct the modal split of business trips, a category of travel that is not included in the Art Cities Research survey. Therefore, we apply data from the annual outbound trip survey conducted in Norway (Statistics Norway, 2019), which provides a breakdown of international trips made by residents into travel purpose and travel mode. Mode choice of business travellers from Norway is not necessarily representative, partly because air travel is more common in Norway than in the rest of Europe and most of the world. That is why we only consider this data as indicative with respect to the use of cars and coaches. Results show that business overnight visitors do not use coaches, and that they have a much lower propensity to use cars and a higher propensity to use airplanes and trains compared to leisure tourists. On this basis, we assume that in the case of international business arrivals, the modal share of coaches would be systematically zero, that the share of car travel would be five times lower compared to leisure arrivals, and that the remaining trips would be shared between airplanes and trains in line with the distribution that was observed for leisure travel. In the case of Brussels-bound trips from France, for example, this leads to an increase in the share of plane travel from $10 \%$ to $20 \%$, while train travel goes up from $35 \%$ to $70 \%$, car travel is reduced from $50 \%$ to $10 \%$ and coach travel from $4 \%$ to $0 \%$.

The modal split of arrivals from countries that were not included in the Art Cities Research survey was reconstructed as follows. In cases where the trip length was less than $1,500 \mathrm{~km}$, we applied the modal split as observed in a country or (sub-national) region located at a comparable distance or in a similar spatial context. As an example, survey figures for Italy were equally applied to tourists from Croatia, figures for Piemonte to Austria, and for Ireland to Northern Ireland. For origins located at a distance between 1,500 and $2,000 \mathrm{~km}$, we applied correction factors derived from a 2014 survey of tourists in the Netherlands which was carried out by NBTC Holland Marketing (2015). The NBTC survey is rare in its kind, since it collects modal split data with respect to countries or country sets of origin. Correction factors were applied for business trips up to $2,000 \mathrm{~km}$. For longer trips, we opted for a maximalist solution, assuming that all trips were made by airplane.

Although one of the most accurate, feasible approximations, it is still important to realize that the outlined method attributes the entirety of emissions associated with travel to Europe to the Brussels-Capital Region as a single destination. It is important to keep in mind that this choice causes an upward bias in the results, which could not be corrected for because of lack of data on multi-destination tours. This is one of the reasons why we want to underline the exploratory nature of our study, and urge the reader to put the results obtained from our calculations in perspective. Also, it is important to bear in mind that the outlined method was only applied to estimate the modal split of tourist arrivals in Brussels in 2018 .

\subsection{Estimating Distance between Origins and Destinations}

Distance calculation between countries and the centre of Brussels was based on centroid locations that were weighted by the geographical distribution of population, as computed by the Center for International Earth Science Information Network of Columbia University. Nevertheless, the distances obtained are still imperfect approximations of actual distances travelled when arriving in Brussels. It not only treats all flights originating from a single country in the same manner, regardless of the (unknown) origin city or region (for example, no distinction is made between New York and Los Angeles in the United States), it is also based on the assumption that air travel is always choosing the shortest path (greatcircle distance). Dobruszkes and Peeters (2019) show that the majority of commercial flights actually take longer routes, which on average adds $7.5 \%$ of distance. Therefore, we have corrected all 'shortest distances' between origins and destinations by means of the distance class-based coefficients as provided by Dobruszkes and Peeters (2019).

\subsection{Climate Footprint per Passenger by Travel Mode}

We distinguished between modes of transport with respect to emission rates per passenger kilometre travelled. We started from the figures provided by Peeters, Szimba, and Duijnisveld (2007), a well-cited source that nonetheless needed a slight update with respect to air and car travel data that date back to 2004. Indeed, both modes mentioned have faced fleet renewal which has led to lower emissions per passenger kilometre during operations. In the case of air transport, we have updated the rates ourselves, based on real air services at Brussels Airport (see Table 1 for more detailed explanation). Depending on the distance, the obtained rates are 15 to 30\% lower than those calculated back in 2004. With respect to car transport, we used the results of a recent study in Denmark (Christensen, 2016), which shows that emissions per passenger kilometre were $25 \%$ lower in 2015 compared to 2004. Updating was not necessary, however, for emissions from trains and buses, as the current figures are very close to those measured in 2004 (see, e.g., Prussi \& Lonza, 2018, for trains; and DEFRA, 2020, for coaches). For overland motor vehicles, only $\mathrm{CO}_{2}$ emissions were calculated, given the limited 
Table 1. Scope, indicators, and data sources.

\begin{tabular}{|c|c|c|}
\hline Dimension & Indicators & Data sources \\
\hline \multirow[t]{2}{*}{$\begin{array}{l}\text { Number of } \\
\text { international } \\
\text { tourists }\end{array}$} & $\begin{array}{l}\text { International tourist arrivals (for } \\
\text { at least one night) in registered } \\
\text { collective accommodation } \\
\text { establishments }\end{array}$ & Statistics Belgium (2019) \\
\hline & $\begin{array}{l}\text { Arrivals by purpose of the trip } \\
\text { (leisure versus business) and } \\
\text { country of residence of the } \\
\text { guest }\end{array}$ & \\
\hline Travel mode & $\begin{array}{l}\text { Travel modal split according to } \\
\text { country of origin }\end{array}$ & $\begin{array}{l}\text { For leisure purposes: Art Cities Research (Tourisme Vlaanderen, } \\
\text { 2018), a survey conducted between April } 2017 \text { and April } 2018 \\
\text { among 1,400 people staying in Brussels for the purpose of leisure. } \\
\text { For business purposes: adaptation of Art Cities Research results } \\
\text { taking into account the annual Travel Survey conducted by } \\
\text { Statistics Norway (2019; trips by mode of transport, type of trip } \\
\text { and contents). }\end{array}$ \\
\hline
\end{tabular}

Distance between origin and destination

Distance between the centre of Brussels and centroid of each country of origin weighted by the spatial distribution of the population

Climate footprint
Climate footprint per passenger kilometre, class of distance, and travel mode
Own calculations based on gridded population datasets (Popgrid Data Collaborative, 2019) provided by the Center for International Earth Science Information Network (2019). For air travel, distance between origin and destination was multiplied by a coefficient to take into account the existence of detours (i.e., longer itineraries than the great-circle distance). We used the coefficients computed by Dobruszkes and Peeters (2019): 1.143 for distance less than $1000 \mathrm{~km}, 1.073$ for $1000-4000 \mathrm{~km}$, and 1.048 for more than 4000 $\mathrm{km}$.

For airplanes: own calculations based on $\mathrm{CO}_{2}$ emissions for all the flights to/from Brussels airport in 2018. The data on the provision of regular air services in Brussels Airport have been extracted from the 2018 OAG Schedules Analyser (OAG, 2018). For each flight, $\mathrm{CO}_{2}$ emissions were calculated by using Eurocontrol Small Emitters Tools (Eurocontrol, 2019). Based on the World airline rankings 2018 (Flightglobal, 2019), a seat occupancy rate of $80 \%$ has been used to estimate the number of passengers for each flight. The calculated emission factors by classes of distance (expressed in $\mathrm{kg}$ $\mathrm{CO}_{2} \mathrm{pkm}$ ) are: 0.144 for distances less than $500 \mathrm{~km}, 0.108$ for $500-1000 \mathrm{~km}, 0.090$ for $1000-1500 \mathrm{~km}, 0.084$ for $1500-2000 \mathrm{~km}$, and 0.093 for more than $2000 \mathrm{~km}$. In a second stage, according to the literature (DEFRA, 2020), the emission factors were multiplied by 1.9 to convert $\mathrm{CO}_{2}$ emissions into $\mathrm{CO}_{2}$ eq ('climate footprint'). contribution of other emissions to the climate footprint. Given the importance of the radiative forcing (RF) effect, however, it would be unacceptable to maintain this simplification with regard to aviation. So, in order to estimate the total climate footprint of air travel, effects caused by non- $\mathrm{CO}_{2}$ forcing agents (nitrogen oxides [ $\mathrm{NO}_{x}$ ], water vapour, soot and sulfate aerosols, contrail cirrus) were accounted for by applying a multiplier of 1.9 to the amount of $\mathrm{CO}_{2}$ emissions, a conversion factor that was derived from Lee et al. (2010) and is recommended by DEFRA (2020). This conversion factor is defined as the ratio between total $\mathrm{CO}_{2}$-warming-equivalent emissions from all forcing agents and those from $\mathrm{CO}_{2}$ alone, with a 100-year time horizon (Global Warming Potential or GWP100). In a recent paper, Lee et al. (2020) have updated their estimates, based on new models of the RF effect of contrail cirrus. When using the same metric (GWP100), the conversion factor obtained is slightly lower (1.7 as opposed to 1.9). However, when using another metric that is assumed to better reflect warming potential under the current growth conditions of air travel, the conversion factor rose to 3.0. On this basis, it is concluded "that aviation emissions are currently warming the climate around three times faster than that associated with aviation $\mathrm{CO}_{2}$ emissions alone" (Lee et al., 2020 , p. 8). Therefore, the climate footprint of aviation 
as an outcome of our analysis likely underestimates the impact of non- $\mathrm{CO}_{2}$ agents. However, given the persistent uncertainties about these impacts, it seems more cautious to use a conversion factor that has been recommended for several years, than one that was only recently published. Besides, taking RF into account is the reason behind the deliberate use of the term 'climate footprint' in this article instead of the more common 'carbon footprint.' Table 1 provides more detail about the sources used and the calculation methods employed.

In order to estimate the entirety of $\mathrm{CO}_{2}$ emissions linked to international tourist arrivals, we have performed the calculation for each of the 247 countries from which overnight visitors arrive in Brussels. First, the number of arrivals was disaggregated by purpose and by travel mode, and for air travel additionally by distance class. Then, results obtained per travel purpose and mode were added up and multiplied by two in order to account for both the inward and the outward trip, as we want to allocate emissions of the entire journey to Brussels.

\section{Results}

\subsection{Amount and Geography of International Arrivals}

In 2018, the Brussels-Capital Region registered around 2.9 million international arrivals in registered tourist accommodation. As such, Brussels represents an important, although not a major, urban destination in Europe. Its attractiveness remains modest not only compared to Paris (13.2 million international arrivals) and London (13.0 million), the two main poles of urban leisure and business travel in Europe, but also compared to cities that are well-established as destinations for tourists from distant markets, both as city-trip destination and as part of intra-European tours, be it individually visited or as part of a group (Rome, 9.6 million arrivals; Barcelona, 7.4 million; Amsterdam, 6.9 million; Prague, 6.7 million; Vienna, 6.3 million; Madrid, 5.2 million; Berlin, 4.9 million; Lisbon, 4.3 million; Venice, 4.3 million; Budapest, 3.8 million). Even Munich and Copenhagen, which are less well-known as international tourist attractions, welcome more international overnight visitors than Brussels. The situation does not change if we account for the size of the city. Indeed, also the number of international arrivals per inhabitant is lower in Brussels than in all cities listed above, except for Budapest.

As shown in Figure 2 and Table 2, the vast majority of international tourists staying in Brussels arrive from a limited number of states: $70 \%$ of arrivals originate from just 12 origins. European states (70.5\% of arrivals), especially neighbouring countries (41\%), are the main source of overnight visitors, whether for leisure or business purposes. Among the most distant origins, the United States $(217,000$ arrivals, $7.7 \%$ of the total), China $(88,000,3.1 \%)$ and to a lesser extent Japan $(48,000$, $1.7 \%)$, Brazil $(41,000,1.4 \%)$, and Russia $(38,000,1.3 \%)$ stand out clearly. The map also highlights the significant volume of arrivals from Canada $(32,000)$, India $(27,000)$, and Australia $(25,000)$.

Given the important presence of international political bodies and the rather limited attractiveness of Brussels as a leisure destination, for decades the number of arrivals with a leisure purpose has been significantly lower than the number of business trips. Since the early 2000s, the ratio between both kinds of travel

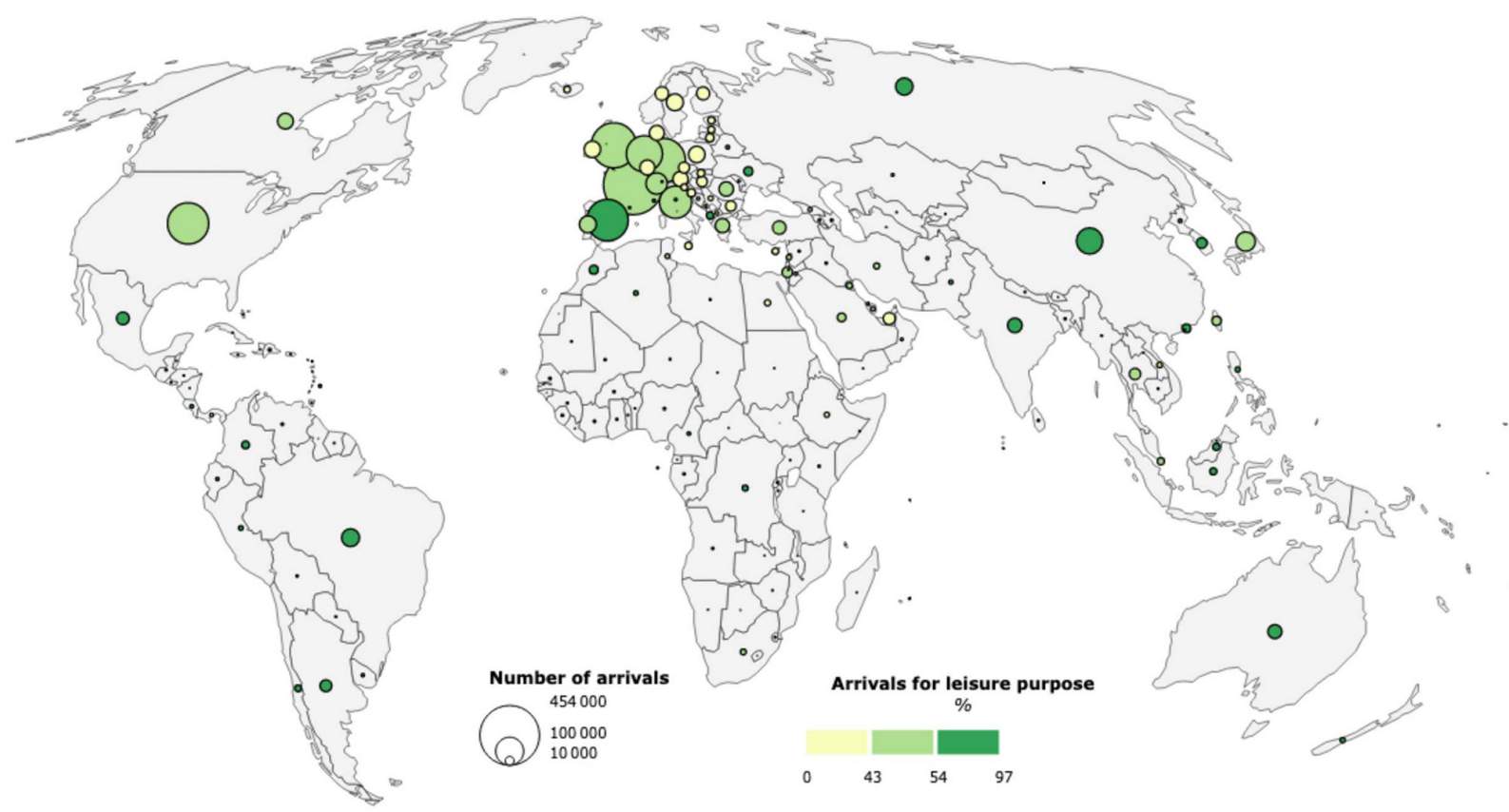

Figure 2. Number of international arrivals in the Brussels-Capital Region by country of residence and by purpose (2018). Source: Statistics Belgium (2019). 
Table 2. International tourist arrivals and associated climate footprint in the Brussels-Capital Region (in 2018) by distance class.

\begin{tabular}{|c|c|c|c|c|c|c|c|c|c|c|}
\hline \multirow[b]{3}{*}{$\begin{array}{c}\text { Distance class } \\
(\mathrm{km})\end{array}$} & \multirow{2}{*}{\multicolumn{3}{|c|}{ International tourist arrivals }} & \multicolumn{7}{|c|}{ Climate footprints } \\
\hline & & & & \multicolumn{2}{|c|}{ For all travel modes } & \multicolumn{5}{|c|}{ By travel mode (\% of total GHG emission) } \\
\hline & $\begin{array}{c}\text { number } \\
(\times 1,000)\end{array}$ & $\%$ & $\begin{array}{c}\text { per } \\
100,000 \\
\text { inh. }\end{array}$ & $\begin{array}{c}\text { Total } \\
\text { (kton } \\
\left.\mathrm{CO}_{2} \mathrm{eq}\right)\end{array}$ & $\begin{array}{c}\text { By tourist } \\
\text { arrival } \\
\text { (kg CO} 2 \mathrm{eq})\end{array}$ & Airplane & Train & Car & Coach & Total \\
\hline$<1,000$ & 1,330 & 47.3 & 486 & 108 & 81 & 2.4 & 0.6 & 0.9 & 0.0 & 4.0 \\
\hline $1,000-1,999$ & 639 & 22.7 & 179 & 242 & 378 & 8.1 & 0.3 & 0.5 & 0.1 & 8.9 \\
\hline $2,000-2,999$ & 71 & 2.5 & 52 & 61 & 868 & 2.3 & & & & 2.3 \\
\hline $3,000-3,999$ & 67 & 2.4 & 20 & 85 & 1,265 & 3.1 & & & & 3.1 \\
\hline $4,000-4,999$ & 32 & 1.1 & 5 & 54 & 1,677 & 2.0 & & & & 2.0 \\
\hline $5,000-5,999$ & 30 & 1.1 & 6 & 59 & 1,975 & 2.2 & & & & .2 \\
\hline $6,000-6,999$ & 40 & 1.4 & 12 & 95 & 2,372 & 3.5 & & & & 3.5 \\
\hline $7,000-7,999$ & 251 & 8.9 & 13 & 680 & 2,707 & 25.2 & & & & 25.2 \\
\hline $8,000-8,999$ & 155 & 5.5 & 8 & 503 & 3,246 & 18.6 & & & & 18.6 \\
\hline $9,000-9,999$ & 119 & 4.2 & 21 & 419 & 3,523 & 15.5 & & & & 15.5 \\
\hline$>10,000$ & 81 & 2.9 & 14 & 396 & 4,911 & 14.7 & & & & 14.7 \\
\hline Total & 2,814 & 100.0 & 37 & 2,701 & 960 & 97.6 & 0.9 & 1.4 & 0.1 & 100.0 \\
\hline
\end{tabular}

Sources: Christensen (2016); Peeters et al. (2007); Statistics Belgium (2019); Toerisme Vlaanderen (2018); World Development Indicators database (World Bank, 2019); and own calculations based on Eurocontrol Small Emitters Tool (Eurocontrol, 2019) and OAG (2018) data.

has gradually become more balanced. Currently, overall shares are more or less equal, although the relative importance between both purposes still depends on the origin (Figure 2). Looking at origin countries, business overnight visitors are generally overrepresented in Europe (except for Spain), the United States, the ArabPersian Gulf countries, and Southeast Asia including Japan, while the reverse is true for arrivals from Latin America, Russia, India, China, Australia, and New Zealand.

In line with related research (e.g., Le \& Nguyen, 2021; $\mathrm{Wu}$, Liao, \& Liu, 2019), we hypothesize that the geography of the origin of the flows of international tourists staying in Brussels results from the combined effects of distance, the economic and population-based potential for sending travellers in the origin countries, and local preferences in terms of destination choice behaviour. In an attempt to disentangle the influence of these different factors, we have broken down international arrivals by distance class (Table 2). The results show that the volume of flows decreases rapidly with distance: Nearly half of the arrivals come from within a radius below $1,000 \mathrm{~km}$ from Brussels, a fifth from a radius between 1,000 and $2,000 \mathrm{~km}$, while barely $2.5 \%$ originates from countries located at a distance between 2,000 and 3,000 km. Beyond 2,000 km, the relationship between distance and number of trips is altered by variations in population size and per capita income between distance classes. The two distance classes between 7,000 and 9,000 km each produce more international overnight visitors to Brussels than those between 2,000 and 7,000 km, because they respectively include India and the United States $(7,000$ to $8,000 \mathrm{~km})$ and China and Brazil (8,000 to $9,000 \mathrm{~km})$. The expected negative relationship between distance and number of arrivals is only partly compensated for by the larger population in more remote distance classes, as shown by the number of arrivals in Brussels per 100,000 inhabitants in the origin classes (Table 2). Indeed, if the relative volume of flows to Brussels decreases steadily up to $5,000 \mathrm{~km}$, it increases between 5,000 and $8,000 \mathrm{~km}$, then again between 9,000 and $10,000 \mathrm{~km}$. These variations result in part from differences in per capita income on number of tourists sent. It is clear that those intermediate distance classes, which represent lower numbers of arrivals per 100,000 inhabitants, are generally characterized by a fairly modest per capita GDP (see for example the classes of 4,000 to $6,000 \mathrm{~km}$ ).

\subsection{Volume and Geography of Climate Footprints}

According to our calculations, international tourist arrivals in the Brussels-Capital Region generated a total of 1,452 kilotonnes of $\mathrm{CO}_{2}$ (or $1.45 \mathrm{Mton} \mathrm{CO}_{2}$ ) in 2018, taking into account both inward and outward trips. After applying the 1.9 multiplicator to air trips, the climate footprint of all international travel to Brussels that is included in our analysis, in 2018, amounts to around 2,701 kilotonnes of $\mathrm{CO}_{2}$ equivalent (i.e., 2.70 Mton $\mathrm{CO}_{2}$ eq), which equals about $73 \%$ of the entire climate footprint (all activities combined, including the residential sector and internal transport, but obviously excluding international travel) that were officially reported by the Brussels-Capital Region in 2018.

Examination of the distribution of the tourisminduced climate footprint reveals a geography that is radically different from the geography of tourist arrivals. In fact, while the number of flows sharply decreases with distance, the amount of emissions increases with distance (Table 3). Thus, while visitor flows from Europe 
Table 3. Geographic origin of international tourist arrivals in the Brussels-Capital Region and climate footprint of these arrivals (2018).

\begin{tabular}{|c|c|c|c|c|c|c|c|c|}
\hline \multirow[t]{3}{*}{$\begin{array}{c}\text { Origin } \\
\text { (country of residence) }\end{array}$} & \multicolumn{3}{|c|}{$\begin{array}{l}\text { Distribution by purpose and } \\
\text { region of origin of international } \\
\text { tourist arrivals in Brussels- } \\
\text { Capital Region (in 2018) (\%) }\end{array}$} & \multicolumn{5}{|c|}{$\begin{array}{l}\text { Distribution by origin of the climate footprint of } \\
\text { international travel towards Brussels-Capital } \\
\text { Region (in 2018) (\% of total climate footprint) }\end{array}$} \\
\hline & \multirow[b]{2}{*}{ Leisure } & \multirow[b]{2}{*}{ Business } & \multirow[b]{2}{*}{ Total } & \multicolumn{5}{|c|}{ All journeys } \\
\hline & & & & Airplane & Train & Car & Coach & Total \\
\hline Neighbouring countries (Europe) & 20.1 & 20.9 & 41.0 & 2.1 & 0.4 & 0.9 & 0.0 & 3.4 \\
\hline Southern Europe & 7.5 & 6.3 & 13.9 & 5.1 & 0.2 & 0.3 & 0.0 & 5.6 \\
\hline Central Europe & 2.0 & 2.7 & 4.7 & 0.6 & 0.1 & 0.1 & 0.0 & 0.8 \\
\hline Northern Europe & 1.9 & 3.4 & 5.3 & 1.9 & 0.0 & 0.2 & 0.0 & 2.2 \\
\hline Eastern Europe & 2.3 & 3.3 & 5.6 & 3.2 & 0.0 & 0.2 & 0.0 & 3.3 \\
\hline Russian realm and Central Asia & 1.1 & 0.9 & 2.1 & 2.5 & & & & 2.5 \\
\hline Indian realm & 0.6 & 0.5 & 1.1 & 3.0 & & & & 3.0 \\
\hline China & 2.1 & 1.4 & 3.5 & 11.5 & & & & 11.5 \\
\hline East Asia and Oceania & 2.1 & 1.5 & 3.6 & 15.7 & & & & 15.7 \\
\hline Southeast Asia & 0.8 & 0.8 & 1.6 & 6.0 & & & & 6.0 \\
\hline Arab-Muslim realm & 1.8 & 2.0 & 3.8 & 5.1 & & & & 5.1 \\
\hline Sub-Saharan Africa & 0.5 & 0.6 & 1.1 & 2.6 & & & & 2.6 \\
\hline North America & 4.0 & 4.8 & 8.8 & 24.1 & & & & 24.1 \\
\hline Latin America and the Caribbean & 2.7 & 1.2 & 3.9 & 14.2 & & & & 14.2 \\
\hline Europe & 33.9 & 36.6 & 70.5 & 12.8 & 0.8 & 1.6 & 0.1 & 15.3 \\
\hline Rest of the world & 15.8 & 13.7 & 29.5 & 84.7 & 0.0 & 0.0 & 0.0 & 84.7 \\
\hline Grand total & 49.7 & 50.3 & 100.0 & 97.5 & 0.8 & 1.6 & 0.1 & 100.0 \\
\hline
\end{tabular}

Sources: Peeters et al. (2007); Statistics Belgium (2019); Toerisme Vlaanderen (2018); and own calculations.

account for $70.5 \%$ of arrivals, they generate barely $15 \%$ of emissions, while flows from outside Europe, which represent less than $30 \%$ of tourists, generate nearly $85 \%$ of the climate footprint.

This striking result can be explained by the specific relation between air transport and climate footprint, which is brought forward by Figure 3, a map that links emissions by origin country to journeys to Brussels. The very significant climate footprint of flows from the United States (21\% of footprint for $7.6 \%$ of flows) and China ( $10 \%$ versus $3 \%$ ) stand out, but so do Japan (6\% versus $1.7 \%$ ) and Australia (5.5\% versus $0.9 \%$ ). Also, one European state is present among the top ten countries in terms of emissions-Spain-which is the only origin country that combines a very large number of tourists to Brussels with an important share of air travel.

\section{Conclusions}

Territorializing the international share of Brussels's climate footprint is not an easy task. In the above analysis, numerous methodological choices had to be made, and furthermore, the scarce availability of data imposes important limitations. In our calculation, we chose to only include the climate footprint of tourists with Brussels as a destination, assuming that the climate footprint of journeys undertaken by Brussels's residents needs to be allocated to the destination territory. Then, we were unable to cover international overnight visitors who stayed in unregistered accommodation, which means that our analysis significantly underestimates the total number of tourists to Brussels. Furthermore, we were not able to redistribute the climate footprint of tourists arriving in Brussels among the often multiple destinations they visit within Europe, which implies that we overestimated the climate footprint of long-distance overnight visitors. We are also aware that the climate footprint resulting from our calculations covers only one, albeit an important, aspect of Brussels's international position. Embedded emissions in imported products were not included, nor was the share of the Brussels economy in the climate footprint of international sea shipping. A last caution that needs to be mentioned is the significant degree of uncertainty associated with the multiplicator (defined as 1.9) that was applied to convert air transport related $\mathrm{CO}_{2}$ emissions into overall climate footprint. Therefore, an important initial conclusion of our study is that resources should be made available to collect better data. An extensive sample of detailed questionnaires about travel itineraries could be obtained from arriving tourists, especially at airports, but also in a variety of other venues, which would lead to more accurate insights. Such information could be supplemented with big data, in particular from mobile telephony that 


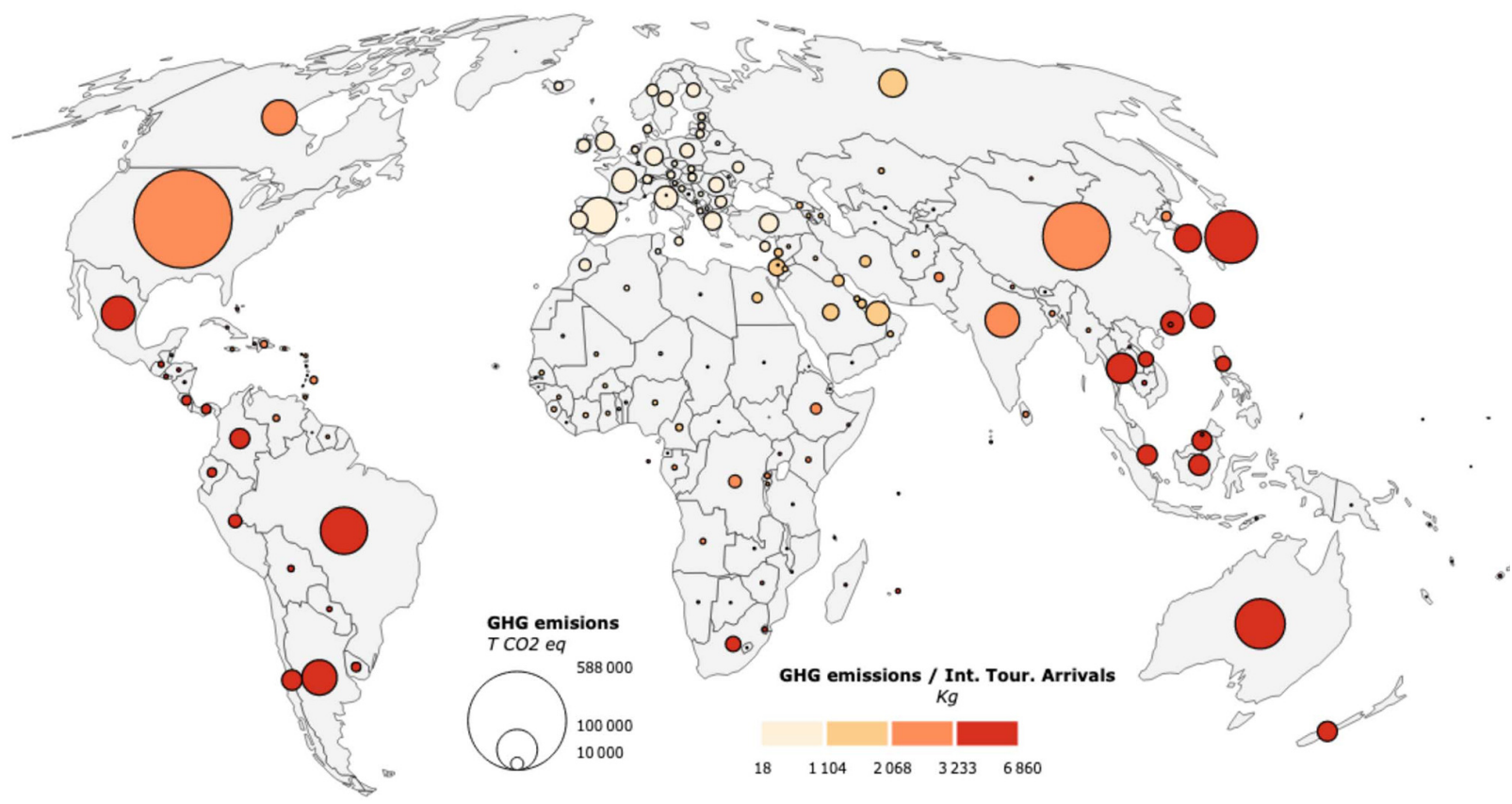

Figure 3. Climate footprint of international travel towards Brussels-Capital Region (in 2018) by country of origin: Absolute amount and amount per international tourist arrival. Sources: Christensen (2016); Peeters et al. (2007); Statistics Belgium (2019); Toerisme Vlaanderen (2018); and own calculations based on Eurocontrol Small Emitters Tool (Eurocontrol, 2019) and OAG (2018) data.

allows to reconstruct travel (see, e.g., Ahas, Aasa, Mark, Pae, \& Kull, 2007; Saluveer et al., 2020).

Despite all reservations that need to be taken into account, and the exploratory nature of our calculations, we can still report a number of interesting findings on the geography and magnitude of the climate footprint of international travel to Brussels. In terms of geographical distribution, over $70 \%$ of international travellers to Brussels come from Europe, while these represent only $15 \%$ of the climate footprint of all international travel to Brussels. It is clear that distance matters. The climate footprint of a journey from a non-European country is not only greater in absolute terms, due to the larger distance, but also in relative terms (expressed in $\mathrm{CO}_{2} \mathrm{eq} / \mathrm{km}$ ) due to the more favourable modal split for intra-European journeys. Besides, we note that Brussels is very conveniently located within Europe, centrally between the two main European travel destinations-London and Parisand with a convenient high-speed train connection to all surrounding major cities. In terms of magnitude, the calculated climate footprint of international journeys with Brussels as a destination equalled 2.7 Mton $\mathrm{CO}_{2}$ eq in the year 2018, which is equivalent to about three quarters of the official total amount of emissions of the BrusselsCapital Region as recorded by the Belgian national climate inventory (3.7 Mton $\mathrm{CO}_{2} \mathrm{eq}$ in 2017). Moreover, emissions from international journeys are increasing at a rapid pace, with an average growth of more than $4 \%$ per year over the past 18 years (up to 2019, before the Covid-19 crisis). If the current growth rate would persist, by 2036 the climate footprint of international travel to
Brussels will be more than twice as high as the official climate footprint of Brussels, a ratio that will be even higher in case the emission reduction targets in the other sectors will be achieved. The problematic nature of this finding is to be nuanced only to a limited extent by the observation that the climate footprint of international journeys to Brussels is smaller, both counted per trip and in total, than that of comparable cities such as Munich, Budapest, or Zurich (Gunter \& Wöber, 2019).

The typical position of Brussels as a centre of political decision-making urges to reflect on the finding that some locations may be better positioned than others to host such functions. Our analysis shows that Brussels is in fact doing remarkably well, since the climate footprint of intra-European travel to Brussels is rather low, while the overall climate footprint of inbound long-distance travel is considerably lower in comparison to other cities with a strong international position. Although Brussels's central location helps keeping modest the climate footprint of its incoming business travel, we should not forget that the favourable score of Brussels compared to cities such as Barcelona, Prague, or Amsterdam is largely due to the relatively limited touristic appeal of Brussels compared to the cities mentioned.

From a wider perspective, we can conclude that in a rapidly globalizing and at the same time warming world, it is no longer tenable to omit territorializing the climate footprint of international transport, while this is wellestablished practice for emissions caused by industrial activities, agriculture, buildings, and domestic transport. Not including these emissions in climate inventories 
leads to major biases in the climate debate itself. While climate movements argue for the adaptation of Global Northern consumption patterns and production processes, a less visible threat seems to be situated in the increasingly globalized and networked nature of society. Dependence on long-distance travel not only makes the economy more carbon intensive, but also education, research, culture, and leisure activities, and even family visits rely ever more on the consumption of tremendous amounts of kerosene. Long-distance travel patterns seem to be increasingly anchored in society, and ever less reversible. And even as for medium-distance journeys in Europe, less carbon-intensive alternatives such as trains and coaches are available, an absolute reduction in the number of aircraft kilometres travelled is a particularly unattractive idea for many citizens, businesses, and organizations, for which broad societal support is virtually non-existent. Nevertheless, it is clear that a carbon neutral future is one where jet aircraft will no longer play a substantial role.

\section{Acknowledgments}

The authors would like to thank Taïs Grippa (ULB-IGEAT) for doing part of the preparatory calculations, Visit Brussels for the valuable data they provided, Frédéric Dobruszkes (ULB-IGEAT) for his valuable suggestions, and the reviewers and editors of the thematic issue for their thoughtful comments that led to a substantial improvement of the article. All remaining errors are sole responsibility of the authors. This research received no external funding.

\section{Conflict of Interests}

The authors declare no conflict of interests.

\section{Supplementary Material}

Supplementary material for this article is available online in the format provided by the authors (unedited).

\section{References}

Achten, W. M., Almeida, J., \& Muys, B. (2013). Carbon footprint of science: More than flying. Ecological Indicators, 34, 352-355.

Afionis, S., Sakai, M., Scott, K., Barrett, J., \& Gouldson, A. (2017). Consumption-based carbon accounting: Does it have a future? Wiley Interdisciplinary Reviews: Climate Change, 8(1), e438.

Ahas, R., Aasa, A., Mark, Ü., Pae, T., \& Kull, A. (2007). Seasonal tourism spaces in Estonia: Case study with mobile positioning data. Tourism Management, 28(3), 989-910.

Arlt, W. G. (2013). The second wave of Chinese outbound tourism. Tourism Planning \& Development, 10(2), 126-133.
Arsenault, J., Talbot, J., Boustani, L., Gonzàles, R., \& Manaugh, K. (2019). The environmental footprint of academic and student mobility in a large researchoriented university. Environmental Research Letters, 14(9), 095001.

Banister, D. (2008). The sustainable mobility paradigm. Transport Policy, 15(2), 73-80.

Becken, S. (2002). Analysing international tourist flows to estimate energy use associated with air travel. Journal of sustainable tourism, 10(2), 114-131.

Bottrill, C., Liverman, D., \& Boykoff, M. (2010). Carbon soundings: Greenhouse gas emissions of the UK music industry. Environmental Research Letters, 5(1), 014019.

Boussauw, K., \& Vanoutrive, T. (2019). Flying green from a carbon neutral airport: The case of Brussels. Sustainability, 11(7), 1-19.

Brussels-Capital Region. (2019). Plan énergie climat 2030: The right energy for your region. Brussels: Brussels-Capital Region.

Bruxelles Environnement. (2019, April 18). Les émissions de gaz à effet de serre en Région de Bruxelles Capitale [Greenhouse gas emissions in the BrusselsCapital region]. Bruxelles Environnement. Retrieved from https://environnement.brussels/thematiques/ air-climat/climat/les-emissions-de-gaz-effet-deserre-en-region-de-bruxelles-capitale

Bui, H. T., \& Trupp, A. (2014). The development and diversity of Asian tourism in Europe: The case of Vienna. International Journal of Tourism Sciences, 14(2), 1-17.

Burtscher, L., Barret, D., Borkar, A. P., Grinberg, V., Jahnke, K., Kendrew, S., . . . McCaughrean, M. J. (2020). The carbon footprint of large astronomy meetings. Nature Astronomy, 4(9), 823-825.

Center for International Earth Science Information Network. (2019). Homepage. Center for International Earth Science Information Network. Retrieved from http://www.ciesin.org

Christensen, L. (2016). Environmental impact of longdistance travel. Transportation Research Procedia, 14, 850-859.

Ciers, J., Mandic, A., Toth, L. D., \& Op't Veld, G. (2019). Carbon footprint of academic air travel: A case study in Switzerland. Sustainability, 11(1), 80.

Collins, A., \& Cooper, C. (2017). Measuring and managing the environmental impact of festivals: The contribution of the ecological footprint. Journal of Sustainable Tourism, 25(1), 148-162.

Collins, A., Munday, M., \& Roberts, A. (2012). Environmental consequences of tourism consumption at major events: An analysis of the UK stages of the 2007 Tour de France. Journal of Travel Research, 51(5), 577-590.

Connolly, M., Dupras, J., \& Séguin, C. (2016). An economic perspective on rock concerts and climate change: Should carbon offsets compensating emissions be included in the ticket price? Journal of Cul- 
tural Economics, 40(1), 101-126.

Czepkiewicz, M., Heinonen, J., \& Ottelin, J. (2018). Why do urbanites travel more than do others? A review of associations between urban form and long-distance leisure travel. Environmental Research Letters, 13(7), 073001.

Davies, J. C., \& Dunk, R. M. (2015). Flying along the supply chain: Accounting for emissions from student air travel in the higher education sector. Carbon Management, 6(5/6), 233-246.

Davis, S. J., \& Caldeira, K. (2010). Consumption-based accounting of $\mathrm{CO}_{2}$ emissions. Proceedings of the National Academy of Sciences, 107(12), 5687-5692.

Dawson, J., Stewart, E. J., Lemelin, H., \& Scott, D. (2010). The carbon cost of polar bear viewing tourism in Churchill, Canada. Journal of Sustainable Tourism, 18(3), 319-336.

Decroly, J.-M., \& Tihon, M. (2019). Enquête sur les visiteurs des musées bruxellois: Rapport global [Survey of visitors to museums of Brussels: General report]. Brussels: Visit Brussels.

DEFRA. (2020). Greenhouse gas reporting: Conversion factors 2020. London: Department for Business, Energy, and Industrial Strategy. Retrieved from https://www.gov.uk/government/publications/ greenhouse-gas-reporting-conversion-factors-2020

Dobruszkes, F., \& Peeters, D. (2019). The magnitude of detours faced by commercial flights: A global assessment. Journal of Transport Geography, 79, 102465.

Dobruszkes, F., Ramos-Pérez, D., \& Decroly, J.-M. (2019). Reasons for flying. In A. Graham \& F. Dobruszkes (Eds.), Air transport: A tourism perspective (pp. 23-39). Amsterdam: Elsevier.

Dube, K., \& Nhamo, G. (2019). Climate change and the aviation sector: A focus on the Victoria Falls tourism route. Environmental Development, 29, 5-15.

Dwyer, L., Forsyth, P., Spurr, R., \& Hoque, S. (2010). Estimating the carbon footprint of Australian tourism. Journal of Sustainable Tourism, 18(3), 355-376.

Eijgelaar, E., Peeters, P., de Bruijn, K., \& Dirven, R. (2017). Travelling large in 2016: The carbon footprint of Dutch holidaymakers in 2016 and the development since 2002. Breda: Breda University of Applied Sciences.

El Hanandeh, A. (2013). Quantifying the carbon footprint of religious tourism: The case of Hajj. Journal of Cleaner Production, 52, 53-60.

Eurocontrol. (2019). Eurocontrol small emitters tool. Eurocontrol. Retrieved from https://www. eurocontrol.int/tool/small-emitters-tool

Fiorello, D., Martino, A., Zani, L., Christidis, P., \& Navajas-Cawood, E. (2016). Mobility data across the EU 28 member states: Results from an extensive CAWI survey. Transportation Research Procedia, 14, 1104-1113.

Flightglobal. (2019). Homepage. Flightglobal. Retrieved from https://www.flightglobal.com

FPS Public Health, Food Chain Safety and Environ- ment. (2019). Belgium's greenhouse gas inventory (1990-2017): National inventory report submitted under the United Nations Framework Convention on Climate Change. Bonn: UNFCCC. Retrieved from https://unfccc.int/sites/default/files/resource/ bel-2019-nir-15apr19.zip

Gössling, S. (2013). National emissions from tourism: An overlooked policy challenge? Energy Policy, 59, 433-442.

Gössling, S., Peeters, P., Ceron, J.-P., Dubois, G., Patterson, T., \& Richardson, R. B. (2005). The eco-efficiency of tourism. Ecological Economics, 54(4), 417-434.

Gunter, U., \& Wöber, K. (2019). Estimating $\mathrm{CO}_{2}$ emissions of European city tourism by source market, travel distance, and transportation mode. Paper presented at the 54th TRC Meeting 2019, Palma de Mallorca, Spain.

Kitamura, Y., Karkour, S., Ichisugi, Y., \& Itsubo, N. (2020). Carbon footprint evaluation of the business event sector in Japan. Sustainability, 12(12), 5001.

Klöwer, M., Hopkins, D., Myles, A., \& Higham, J. (2020). An analysis of ways to decarbonize conference travel after COVID-19. Nature, 2020(583), 356-360.

Larsson, J., Elofsson, A., Sterner, T., \& Åkerman, J. (2019). International and national climate policies for aviation: A review. Climate Policy, 19(6), 787-799.

Larsson, J., Kamb, A., Nässén, J., \& Åkerman, J. (2018). Measuring greenhouse gas emissions from international air travel of a country's residents methodological development and application for Sweden. Environmental Impact Assessment Review, 72, 137-144.

Le, T.-H., \& Nguyen, C. P. (2021). The impact of tourism on carbon dioxide emissions: Insights from 95 countries. Applied Economics, 53(2), 235-261.

Lee, D. S., Fahey, D. W., Skowron, A., Allen, M. R., Burkhardt, U., Chen, Q., . . Wilcox, L. J. (2020). The contribution of global aviation to anthropogenic climate forcing for 2000 to 2018. Atmospheric Environment, 244, 117834.

Lee, D. S., Pitari, G., Grewe, V., Gierens, K., Penner, J. E., Petzold, A., . . . Sausen, R. (2010). Transport impacts on atmosphere and climate: Aviation. Atmospheric Environment, 44(37), 4678-4734.

Lenzen, M., Sun, Y.-Y., Faturay, F., Ting, Y.-P., Geschke, A., \& Malik, A. (2018). The carbon footprint of global tourism. Nature Climate Change, 8(6), 522-528.

Luo, F., Becken, S., \& Zhong, Y. (2018). Changing travel patterns in China and 'carbon footprint' implications for a domestic tourist destination. Tourism Management, 65, 1-13.

NBTC Holland Marketing. (2015). 2014 inbound tourism survey: A closer look at our international visitors. The Hague: Netherlands Board of Tourism \& Conventions.

Nevins, J. (2014). Academic jet-setting in a time of climate destabilization: Ecological privilege and professional geographic travel. The Professional Geographer, 66(2), 298-310. 
OAG. (2018). OAG schedules analyser. OAG. Retrieved from https://www.oag.com/schedules-analyzer

Ottelin, J., Ala-Mantila, S., Heinonen, J., Wiedmann, T., Clarke, J., \& Junnila, S. (2019). What can we learn from consumption-based carbon footprints at different spatial scales? Review of policy implications. Environmental Research Letters, 14(9), 093001.

Patterson, M., \& McDonald, G. W. (2004). How clean and green is New Zealand tourism? Lifecycle and future environmental impacts. Canterbury: Manaaki Whenua Press.

Peeters, P., \& Schouten, F. (2006). Reducing the ecological footprint of inbound tourism and transport to Amsterdam. Journal of Sustainable Tourism, 14(2), 157-171.

Peeters, P., Szimba, E., \& Duijnisveld, M. (2007). Major environmental impacts of European tourist transport. Journal of Transport Geography, 15(2), 83-93.

Pendzialek, B. (2016). Mainland Chinese outbound tourism to Europe: Recent progress. In X. R. Li (Ed.), Chinese outbound tourism 2.0 (pp. 189-206). Oakville: Apple Academic Press.

Pereira, R. P. T., Filimonau, V., \& Ribeiro, G. M. (2019). Score a goal for climate: Assessing the carbon footprint of travel patterns of the English Premier League clubs. Journal of Cleaner Production, 227, 167-177.

Poom, A., Orru, K., \& Ahas, R. (2017). The carbon footprint of business travel in the knowledge-intensive service sector. Transportation Research Part D, 50, 292-304.

Popgrid Data Collaborative. (2019). Homepage. Popgrid. Retrieved from https://www.popgrid.org

Prussi, M., \& Lonza, L. (2018). Passenger aviation and high speed rail: A comparison of emissions profiles on selected European routes. Journal of Advanced Transportation, 2018, 6205714.

Rico, A., Martínez-Blanco, J., Montlleó, M., Rodríguez, G., Tavares, N., Arias, A., \& Oliver-Solà, J. (2019). Carbon footprint of tourism in Barcelona. Tourism Management, 70, 491-504.

Saluveer, E., Raun, J., Tiru, M., Altin, L., Kroon, J., Snitsarenko, T., ... Silm, S. (2020). Methodological framework for producing national tourism statistics from mobile positioning data. Annals of Tourism Research, 81, 102895.

Sharp, H., Grundius, J., \& Heinonen, J. (2016). Carbon footprint of inbound tourism to Iceland: A consumptionbased life-cycle assessment including direct and indirect emissions. Sustainability, 8(11), 1147.

Shields, R. (2019). The sustainability of international higher education: Student mobility and global climate change. Journal of Cleaner Production, 217, 594-602.

Smith, I. J., \& Rodger, C. J. (2009). Carbon emission offsets for aviation-generated emissions due to international travel to and from New Zealand. Energy Policy, 37(9), 3438-3447.

Statistics Belgium. (2019). Tourist accommodations.
Statistics Belgium. Retrieved from https://statbel. fgov.be/en/themes/enterprises/touristaccommodations

Statistics Norway. (2019). Transport and tourism: Travel survey. Statistics Norway. Retrieved from https:// www.ssb.no/en/reise

Sun, Y.-Y. (2014). A framework to account for the tourism carbon footprint at island destinations. Tourism Management, 45, 16-27.

Sun, Y.-Y., Cadarso, M. A., \& Driml, S. (2020). Tourism carbon footprint inventories: A review of the environmentally extended input-output approach. Annals of Tourism Research, 82, 102928).

Sun, Y. Y., \& Drakeman, D. (2020). Measuring the carbon footprint of wine tourism and cellar door sales. Journal of Cleaner Production, 266, 121937.

Sun, Y. Y., \& Pratt, S. (2014). The economic, carbon emission, and water impacts of Chinese visitors to Taiwan: Eco-efficiency and impact evaluation. Journal of Travel Research, 53(6), 733-746.

Toerisme Vlaanderen. (2018). Art Cities Research 2018. Brussels: Toerisme Vlaanderen. Retrieved from https://www.toerismevlaanderen.be/sites/ toerismevlaanderen.be/files/assets/documents_ KENNIS/onderzoeken/Art_citiesresearch_18.pdf

Van Parijs, P., \& Van Parys, J. (2010). Brussels, capital of Europe: A sustainable choice? Brussels Studies, 2010(38), 1-14.

Warnecke, C., Schneider, L., Day, T., La Hoz Theuer, S., \& Fearnehough, H. (2019). Robust eligibility criteria essential for new global scheme to offset aviation emissions. Nature Climate Change, 9(3), 218-221.

Wayens, B., Decroly, J.-M., Strale, M., da Schio, N., Keserü, I., Wiegmann, M., \& Perilleux, H. (2020). Pedestrianisation of a multifunctional space: Challenges and early observations of the Brussels Pentagon. In S. Vermeulen, A. M. Mezoued, \& J.-P. De Visscher (Eds.), Towards a metropolitan city centre for Brussels (pp. 137-160). Brussels: VUBPRESS.

Wolrath Söderberg, M., \& Wormbs, N. (2019). Grounded: Beyond flygskam. Brussels and Stockholm: European Liberal Forum and Fores.

Wood, F. R., Bows, A., \& Anderson, K. (2010). Apportioning aviation $\mathrm{CO} 2$ emissions to regional administrations for monitoring and target setting. Transport Policy, 17(4), 206-215.

World Bank. (2019). World development indicators. World Bank. Retrieved from https://databank. worldbank.org/source/world-developmentindicators

World Tourism Organization. (2010). International recommendations for tourism statistics 2008. New York, NY: United Nations. Retrieved from https:// unstats.un.org/unsd/publication/Seriesm/SeriesM_ 83rev1e.pdf

Wu, C., Liao, M., \& Liu, C. (2019). Acquiring and geovisualizing aviation carbon footprint among urban agglomerations in China. Sustainability, 11(17), 1515. 
Wynes, S., Donner, S. D., Tannason, S., \& Nabors, N. (2019). Academic air travel has a limited influence on professional success. Journal of Cleaner Production, 226, 959-967.
Xiang, Y. (2013). The characteristics of independent Chinese outbound tourists. Tourism Planning \& Development, 10(2), 134-148.

\section{About the Authors}

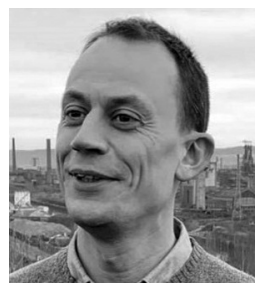

Kobe Boussauw is Assistant Professor of Spatial Planning and Mobility, affiliated with the Cosmopolis Center for Urban Research at the Vrije Universiteit Brussel. His policy-oriented research focuses on the mutual interaction between mobility and the built environment. Central themes in his work are proximity as a quality of the built environment, urban liveability, and sustainability.

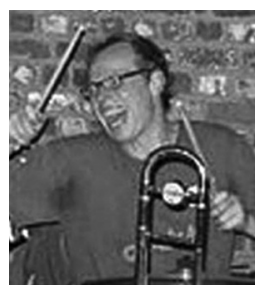

Jean-Michel Decroly is Professor of Human Geography, Demography, and Tourism Studies at the Université Libre de Bruxelles (ULB). He is also Director of the Applied Geography and Geomarketing Research Unit (IGEAT-DGES-Faculty of Sciences) there. His research interests are demographic, urban, and tourism dynamics in Europe, with a focus on spatial differentiation in relation to contemporary transformations of the capitalist system. 